\title{
Lower Eyelid
}

National Cancer Institute

\section{Source}

National Cancer Institute. Lower Eyelid. NCI Thesaurus. Code C49580.

The small thin membrane of skin extending from below the orbit and that covers the bottom portion of the eye. 